\title{
Electromyographic Case Study of Recovery of Walking in an Elderly Man after Cerebral Infarction
}

\author{
Kayoko Окамото ${ }^{1)}$, Tsutomu Oкамото ${ }^{2)}$, Ryokei Ogawa ${ }^{1)}$ \\ ${ }^{1)}$ Department of Orthopaedic Surgery, Kansai Medical University, Fumisono-cho, Moriguchi, \\ Osaka 570-8506, Japan. TEL +81 6-992-1001 \\ ${ }^{2)}$ Department of Liberal Arts, Kansai Medical University
}

\begin{abstract}
To study the recovery of walking in an 85 year old man who had right hemiplegia after suffering a cerebral infarction, electromyograms (EMGs) were recorded from his leg muscles. We used signs for instability that we derived from EMG patterns seen in the developmental process of normal infants. The myoelectric activity at one month after the stroke showed many patterns indicative of unstable walking, closely resembling activity patterns seen in very unstable independent gait of a one year old baby in the first month of learning to walk. Seven months later, these patterns indicating unstable gait tended to have decreased or disappeared, although some marked activity betraying instability still remained. However, when the patient walked with the support of a hand cart and was able to hold his trunk upright, these excessive muscular activities decreased or disappeared, closely resembling the stable adult walking pattern. We recommend further study of the evaluation of recovery of walking after stroke by comparing the patient's EMG patterns to those not only of normal adult human gait, but also of the development of human walking in early childhood.
\end{abstract}

Key words: Gait, EMG, Walking stability, Elderly man, Rehabilitation, Stroke.

(This article was submitted Dec. 8, 1997, and was accepted Feb. 20, 1998)

\section{INTRODUCTION}

To recover gait in hemiplegic patients, it is desirable to start rehabilitation as soon as possible after the stroke. Gait analysis after stroke has been studied by film, temporal patterns, footprints, gas metabolism, electromyography, and other methods of mechanical, anatomical, and physiological analysis ${ }^{1-7)}$. However, few studies have thus far been done on electromyographic evaluation of recovery of walking after stroke.

We have studied EMG activity in normal infants from the time they first walk independently until they display adult-like walking patterns ${ }^{8-10)}$. We have become able to determine signs of unstable walking from EMG activity patterns based on the developmental process of normal infants (Table 1, unpublished). We were interested in examining gait in elderly persons, especially those undergoing a process of rehabilitation in walking, and we wanted to consider the appropriateness of using our signs for instability derived from the EMG patterns seen in the developmental process. The purpose of this study was to consider electromyographically recovery of walking in an elderly man undergoing rehabilitation after suffering a cerebral infarction.

\section{CASE STUDY}

The patient was an 85 year old man who had right hemiplegia after suffering a cerebral infarction. Slight spasticity was seen at one month after onset of the stroke, but coordination in walking 
Table 1. EMG patterns of unstable walking

\begin{tabular}{|c|c|c|c|}
\hline & & Sign of instability and when it normally disappears & Interpretation \\
\hline \multirow{3}{*}{$\begin{array}{l}\text { Ankle } \\
\text { muscles }\end{array}$} & ST-TA & $\begin{array}{l}\text { Activity in the TA during ST } \\
\text { begins to decrease or disappear at about } 1 \text { month after learning to walk }\end{array}$ & $\begin{array}{l}\text { Very } \\
\text { unstable }\end{array}$ \\
\hline & SW-LG & $\begin{array}{l}\text { Activity in the LG during the latter part of SW } \\
\text { begins to decrease or disappear at about } 2-3 \text { months after learning to walk }\end{array}$ & Unstable \\
\hline & ST-LG & $\begin{array}{l}\text { Activity in the LG during the first half of ST } \\
\text { begins to decrease or disappear at about } 3 \text { years of age }\end{array}$ & $\begin{array}{l}\text { Slightly } \\
\text { unstable }\end{array}$ \\
\hline \multirow{2}{*}{$\begin{array}{l}\text { Knee } \\
\text { muscles }\end{array}$} & SW-VM & $\begin{array}{l}\text { Activity in the VM during the latter part of SW } \\
\text { begins to decrease or disappear at about } 1 \text { month after learning to walk }\end{array}$ & $\begin{array}{c}\text { Very } \\
\text { unstable }\end{array}$ \\
\hline & ST-VM & $\begin{array}{l}\text { Activity in the VM during ST } \\
\text { begins to decrease or disappear at about } 1 \text { month after learning to walk }\end{array}$ & $\begin{array}{c}\text { Very } \\
\text { unstable }\end{array}$ \\
\hline \multirow{2}{*}{$\begin{array}{l}\text { Knee \& hip } \\
\text { muscles }\end{array}$} & ST-RF & $\begin{array}{l}\text { Activity in the RF simulteneously with the TA during ST } \\
\text { begins to decrease or disappear at about } 1 \text { month after learning to walk }\end{array}$ & $\begin{array}{c}\text { Very } \\
\text { unstable }\end{array}$ \\
\hline & ST-BF & $\begin{array}{l}\text { Activity in the BF during ST } \\
\text { begins to decrease or disappear at about } 3 \text { years of age }\end{array}$ & $\begin{array}{l}\text { Slightly } \\
\text { unstable }\end{array}$ \\
\hline $\begin{array}{l}\text { Hip } \\
\text { muscles }\end{array}$ & ST-GM & $\begin{array}{l}\text { Activity in the GM during ST } \\
\text { begins to decrease or disappear at about } 3 \text { years of age }\end{array}$ & $\begin{array}{l}\text { Slightly } \\
\text { unstable }\end{array}$ \\
\hline
\end{tabular}

ST: stance phase, SW: swing phase, TA: tibialis anterior, LG: lateral gastrocnemius, VM: vastus medialis, RF: rectus femoris, BF: biceps femoris, GM: gluteus maximus.
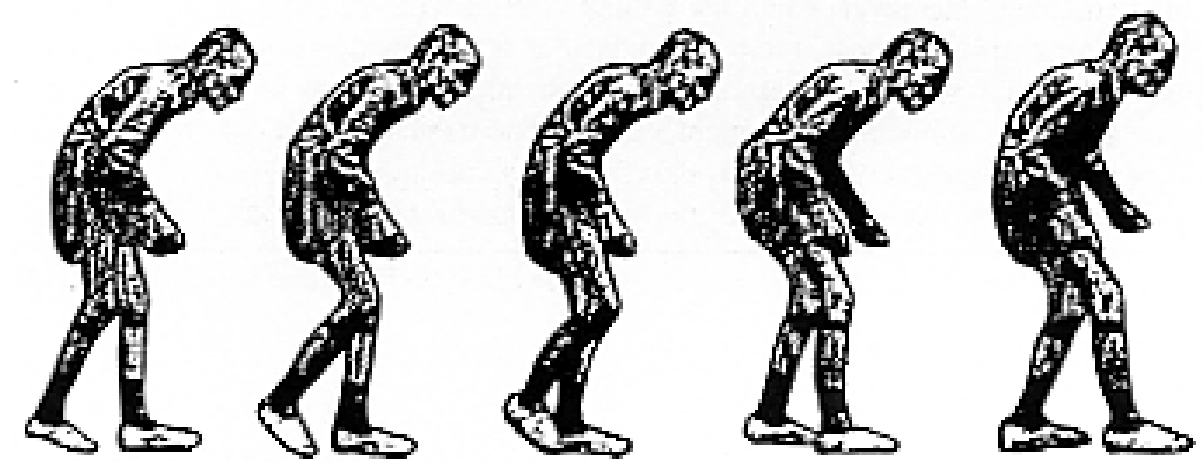

Fig. 1. Form of walking at 1 month after cerebral infarction.

was almost normal. He usually displayed heel contact and a heel-to-toe pattern in gait. His walking posture was characterized by a markedly forward lean of the trunk and a slight squat (Fig. 1).

After the stroke he had slight dementia, so it was hazardous to let him live by himself. He needed assistance or supervision in his daily life.

In the first month of recovery, the patient was given training to enhance activity of the tibialis anterior. He was instructed to do heel walking with support. Training also included trunk function and balance. At 2-3 weeks after the stroke, he could perform supported walking using a parallel bar, and by 1 month he had recovered independent walking. We recorded electromyograms (EMGs) of the independent walking at 1 month after the stroke.

EMGs were recorded three times: one month after the stroke, seven months after the stroke, and one year seven months after the stroke. The EMGs were recorded bilaterally with surface electrodes on the tibialis anterior (TA), lateral gastrocnemius (LG), vastus medialis (VM), rectus femoris (RF), biceps femoris (BF), and gluteus maximus (GM). 


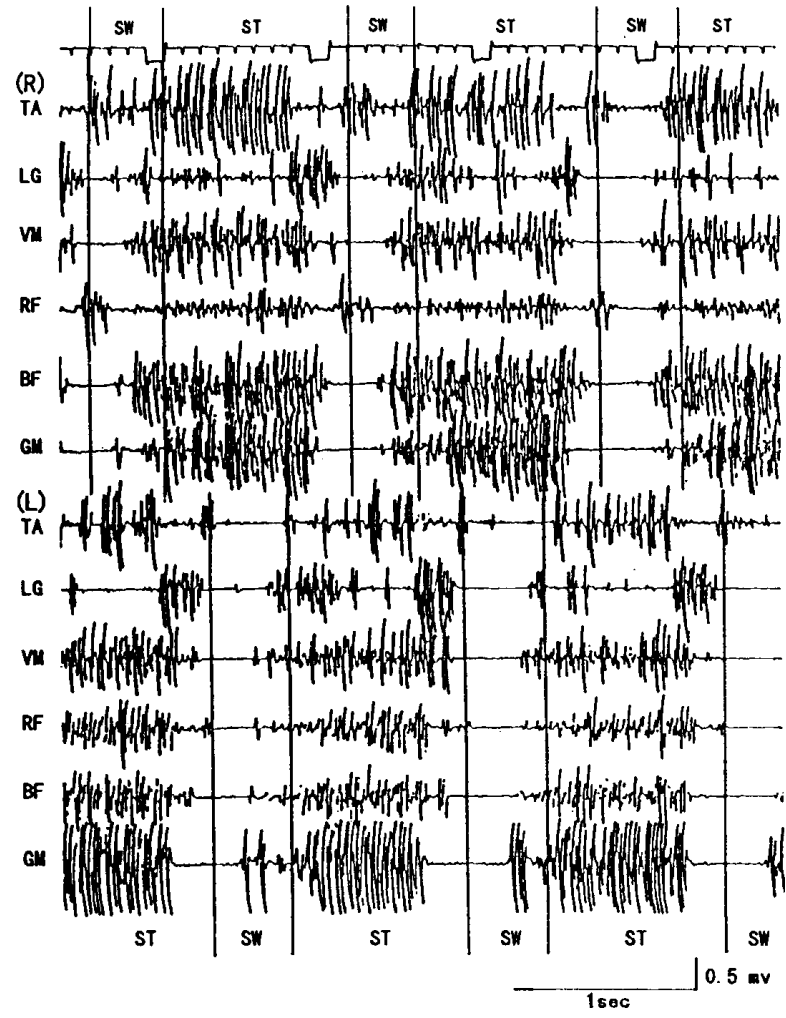

Fig. 2. EMGs of walking at 1 month after stroke. (R): Right leg; affected limb, (L): Left leg; normal limb. ST: stance phase, SW: swing phase, TA: tibialis anterior, LG: lateral gastrocnemius, VM: vastus medialis, RF: rectus femoris, BF: biceps femoris, GM: gluteus maximus.

Skin impedance was lowered by scratching the electrode loci lightly with a needle ${ }^{11)}$. Simultaneously with the EMGs we took video recordings, heel and toe contact data of both feet with the floor, and angular changes of the ankle, knee, and hip joints.

To more closely examine the electromyographic characteristics of the walking stability in the patient, he was instructed to walk with a hand cart for support, keeping his trunk upright.

First of all, we need to review certain salient features of normal stable adult walking, 12-17). The discharge patterns of both the TA and LG in movement at the ankle joint show a generally reciprocal relationship. The TA discharges through most of the swing phase and in the first half of stance phase, and then the LG becomes strongly active in the latter part of stance phase. Knee and hip muscles, such as the VM, BF, and GM, exhibit activity together during the transition from swing to stance phase. In the description that follows, we focus attention on EMG activity patterns seen in the patient that deviate from normal adult walking.

\section{1) 1 month after the stroke}

The subject had difficulty walking, writing, and eating by himself, but recovered independent walking by 1 month after the stroke. Fig. 2 shows representative EMGs of walking at 1 month after the stroke. The walking velocity was about 50-55 $\mathrm{m} / \mathrm{min}$. His walking form was characterized by a marked forward lean of the trunk, a slight squat, and a short step length. He generally contacted the floor with the heel first, barely clearing the floor with the toes, but his foot occasionally hit the ground with the toes first or with the entire sole (Fig. 1).

In swing phase, the LG of either leg showed activity in the latter half of that phase, but in some instances this activity was absent on either side. At the knee, the VM on the right affected side also showed strong activity in the latter half of swing phase. On the sound left side, however, the VM did not exhibit such activity, but rather it showed discharges just prior to heel contact as in normal adult walking.

In stance phase, at either ankle, the TA was continuously active from heel contact until push off. The LG was frequently active, on either side, in the first half of stance phase, but instances of no discharge were also seen on either side. At the knee and hip, the VM, RF, BF, and GM bilaterally showed strong cocontractile patterns in stance phase.

\section{2) 7 months after the stroke}

Fig. 3 shows representative EMGs of walking at 7 months after the stroke. The gait pattern was similar to that at 1 month after the stroke, but heel contact became very consistent, with rare instances of initial contact by the entire sole or toes.

In swing phase, the LG of the affected right leg continued to exhibit excessive activity in the latter half of the phase, but the corresponding myoelectric discharge pattern of the left LG had begun to disappear. The strong burst of activity in the VM of right leg observed at one month after the stroke was no longer seen in the latter half of swing phase, but instead a burst was observed just prior to heel contact as in normal adult walking. 


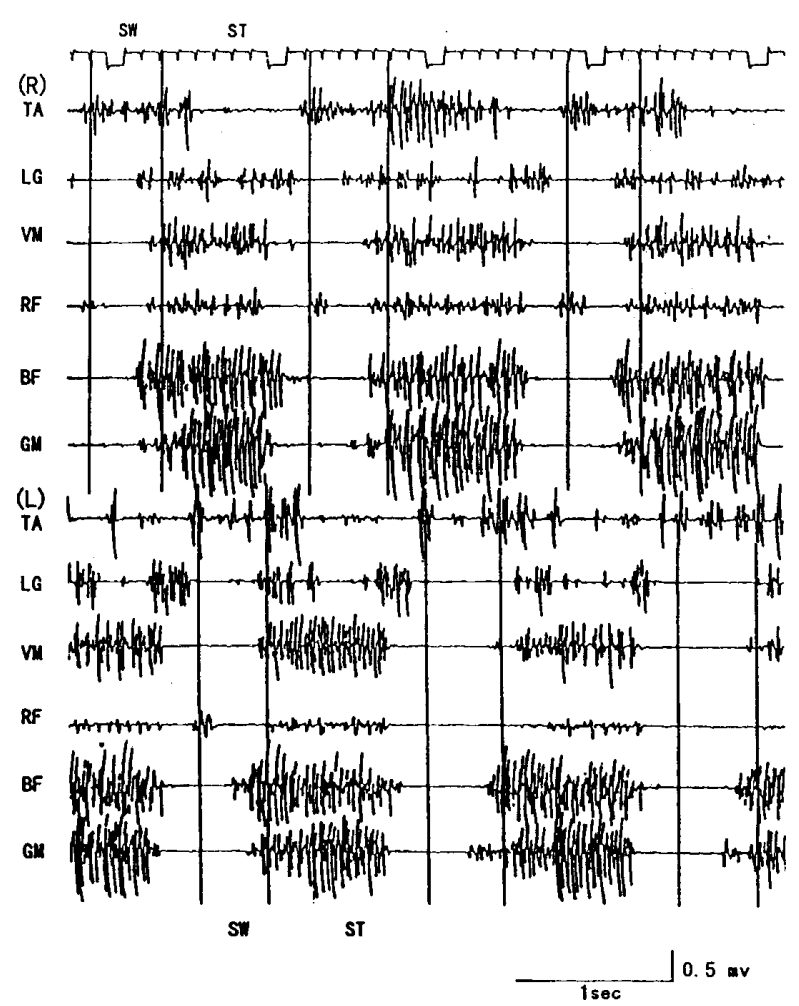

Fig. 3. EMGs of walking at 7 months after stroke. Abbreviations are the same as those in Fig. 2.

In stance phase, the strong continuous discharge patterns of the TA seen in both legs one month after the stroke tended to decrease or even disappear. These discharge patterns were similar to the normal adult pattern, but marked activity could still occasionally be seen in the TA during stance phase on either side. The LG on both sides showed strong activity at the beginning of stance phase. The VM, BF, and GM on either side still exhibited marked cocontractions throughout stance phase, but the excessive continuous discharge patterns of the RF on either side seen at one month after the stroke tended to decrease.

\section{3) 1 year 7 months after the stroke}

Fig. 4 shows representative EMGs of walking at 1 year 7 months after the stroke. The gait pattern resembled that at 7 months after the stroke.

In swing phase, the LG of the affected right leg still showed discharges in the latter half of swing phase as in the recordings of the previous two occasions, but the magnitude of that activity was decreased or sometimes even absent. On the other

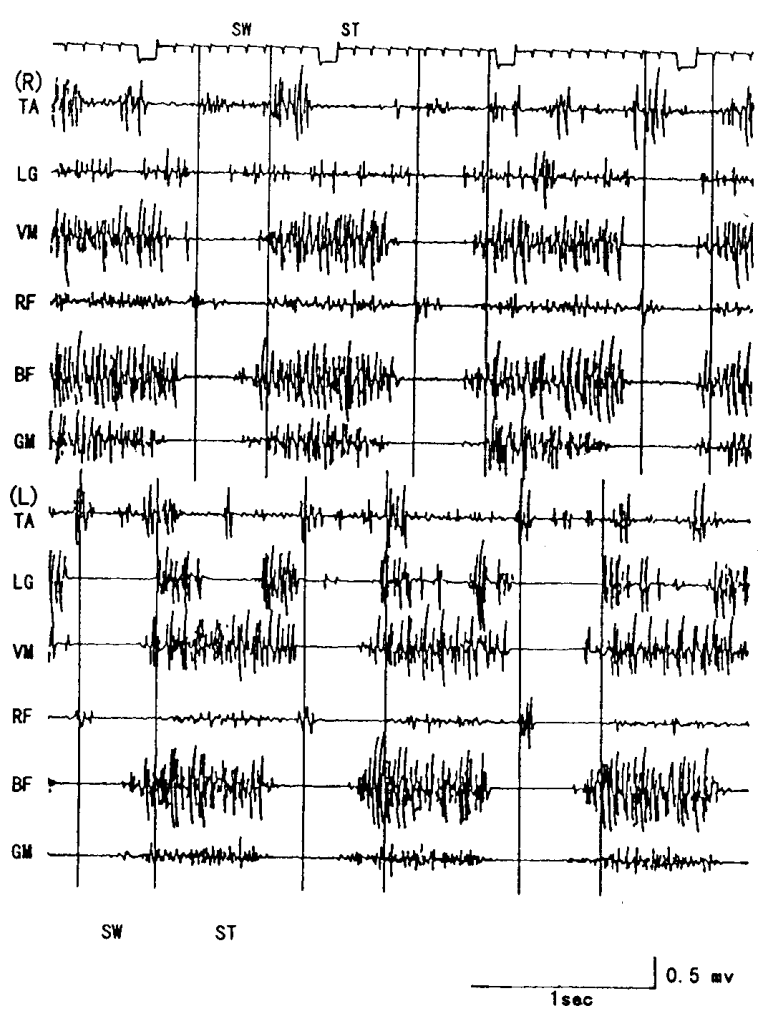

Fig. 4. EMGs of walking at 1 year 7 months after stroke. Abbreviations are the same as those in Fig. 2.

hand, activity of the LG on the sound left side was not usually seen, thus resembling the pattern seen in normal adult gait.

In stance phase, excessive discharge of the LG seen at the beginning of the phase on either side looked like the pattern at 1 month and at 7 months after the stroke. The VM, BF, and GM on either side, as before, showed excessive continuous cocontractile patterns in stance phase.

Table 2 shows in brief the results of evaluating the patient's gait based on our criteria for walking stability. The myoelectric activity at one month after the stroke showed many patterns indicative of unstable walking. Seven months later, these patterns indicating unstable gait tended to decrease or disappear, but the overall picture was still one of a more unstable walking pattern than normal adult gait.

\section{DISCUSSION}

One purpose of gait evaluation is to describe how a patient's performance differs from "normal" 
Table 2. Electromyographic evaluation of walking stability Right leg: affected limb

\begin{tabular}{cccc}
\hline $\begin{array}{c}\text { EMG pattern } \\
\text { of unstable } \\
\text { walking }\end{array}$ & $\begin{array}{c}\text { 1 month } \\
\text { after stroke }\end{array}$ & $\begin{array}{c}7 \text { months } \\
\text { after stroke }\end{array}$ & $\begin{array}{c}1 \text { year } \\
7 \text { months } \\
\text { after stroke }\end{array}$ \\
\hline ST-TA & $(++)$ & $(-)$ partly $(+)$ & $(-)$ p partly (+) \\
SW-LG & $(+)$. partly (-) & $(+)$. partly $(-)$ & $(+)$. partly (-) \\
ST-LG & $(++)$. partly (-) & $(+)$ & $(+)$ \\
SW-VM & $(+)$ & $(-)$ & $(-)$ \\
ST-VM & $(++)$ & $(++)$ & $(++)$ \\
ST-RF & $(+)$ & $(+)$ & $(+)$ \\
ST-BF & $(++)$ & $(++)$ & $(++)$ \\
ST-GM & $(++)$ & $(++)$ & $(++)$ \\
\hline
\end{tabular}

Left leg: normal limb

\begin{tabular}{lccc}
\hline $\begin{array}{c}\text { EMG pattern } \\
\text { of unstable } \\
\text { walking }\end{array}$ & $\begin{array}{c}\text { 1 month } \\
\text { after stroke }\end{array}$ & $\begin{array}{c}7 \text { months } \\
\text { after stroke }\end{array}$ & $\begin{array}{c}1 \text { year } \\
7 \text { months } \\
\text { after stroke }\end{array}$ \\
\hline ST-TA & $(++)$ & $(-)$ partly $(+)$ & $(-)$ partly (+) \\
SW-LG & $(+)$. partly $(-)$ & $(-)$ & $(-)$ \\
ST-LG & $(++)$. partly $(-)$ & $(++)$ & $(++)$ \\
SW-VM & $(-)$ & $(-)$ & $(-)$ \\
ST-VM & $(++)$ & $(++)$ & $(++)$ \\
ST-RF & $(++)$ & $(+)$ & $(+)$ \\
ST-BF & $(++)$ & $(++)$ & $(++)$ \\
ST-GM & $(++)$ & $(++)$ & $(+)$ \\
\hline
\end{tabular}

$(++)$ : marked activity, $(+)$ : noticeable activity, $(-)$ : no activity See Table 1 for descriptions of the EMG patterns.

gait. Generally, normal adults show regular reciprocal discharge patterns of agonists and antagonists during the gait cycle ${ }^{9,12-17)}$. If an individual cannot maintain dynamic stability because of a central nervous disorder or aging, some EMG activities not usually seen in the adult pattern should appear ${ }^{16-19)}$. In our case study, excessive muscular activities appeared early in the recovery period after a stroke (Fig. 2).

In the latter half of swing phase, the VM and LG showed activities not ordinarily seen in the adult. These discharge patterns were similar to those seen at the onset of very unstable independent walking in early child development ${ }^{9,}$ 10). That is, activity of the VM is observed in the latter half of swing phase until about one month after first learning to walk, whereas activity from the LG in the latter half of swing phase continues until about two or three months after learning to walk. As Okamoto et al. $\left.{ }^{9}, 10\right)$ have pointed out, these patterns may be considered to come from the knee extending and the ankle plantarflexing to prevent falling. These excessive muscular activities decrease or disappear when the child is given external support ${ }^{9}$, so these EMG patterns in the latter half of swing phase suggest unstable walking.

In a patient who has suffered a stroke, excessive plantarflexion on the affected side is one typical problem. In our patient, activity of the LG was observed in the latter half of swing phase bilaterally one month after the stroke. At seven months after the stroke, the excessive activity was still found in the right LG, but no longer in the left LG. Stability had thus returned to the extent that indirect effects of the stroke on the sound side had disappeared and the patient was experiencing disability more from the direct effects on the affected side alone.

In stance phase, the TA showed strong activity not usually seen except at the beginning and end of the phase in the adult. This discharge pattern was also similar to that seen in the first month of independent walking by a baby9,10). This activity might be interpreted as an effort to maintain balance with the toes gripping the surface. The LG also exhibited strong activity not seen at the beginning of the phase in normal adult gait, similar to what occurs in small children until around 3 years of age ${ }^{9,10)}$. Since the cocontraction of the TA and LG in stance phase decreases or disappears in stable supported walking of a baby ${ }^{9)}$ and the patient (Fig. 5), those patterns of excessive myoelectric activity are indicative of an unstable walking pattern. To efficiently control body balance in various postures, the TA and LG should operate in reciprocal patterns ${ }^{9,15)}$. Cocontraction of these two muscles suggests effort to stabilize the ankle joint ${ }^{9,}, 10$ ). In our patient strong continuous discharges of the TA were observed bilaterally in stance phase 1 month after the stroke. At 7 months after the stroke, such excessive patterns of the TA during stance phase, suggesting very unstable walking, rarely appeared on either side, indicating that walking at this stage was much closer to normal.

The elderly subject in this study had a forward posture with slightly flexed knees, a tendency pointed out by Critchley ${ }^{20}$.

In stance phase, activity of the VM not seen in normal adult gait was strong and continuous, resembling the pattern seen in a baby during the very first month of independent walking9, 10). This muscle activity might be interpreted as helping to maintain balance with slightly flexed knees. Simi- 

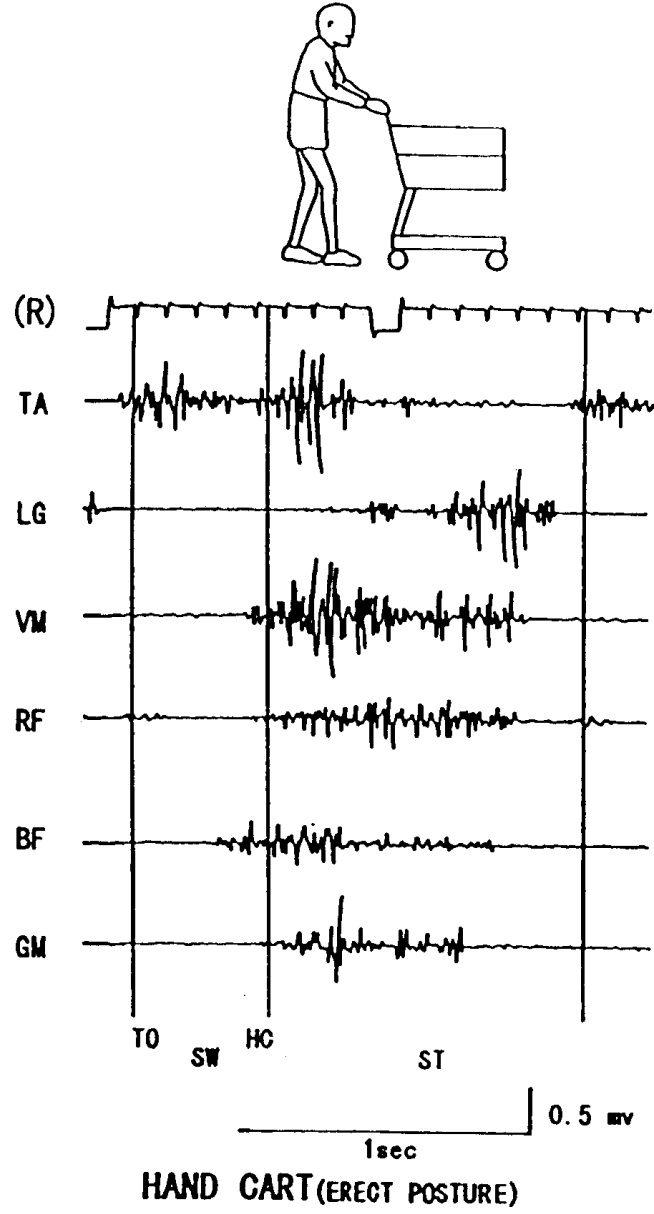

Fig. 5. EMGs of the right leg during supported walking at 1 year 7 months after stroke. TO: toe off, HC: heel contact. Other abbreviations are the same as those in Fig. 2.

larly, strong continuous activity of the LG, BF, and GM in our patient not seen in the normal adult were like the activities of these muscles seen in small children until around 3 years of age ${ }^{9,10)}$. Such activities of these antigravity muscles might be attributable to the patient's forward posture. When the patient used support while walking and attained an upright posture, the excessive activities of these muscles tended to decrease or disappear, looking instead like the stable normal adult pattern (Fig. 5). These excessive discharge patterns of the $\mathrm{VM}, \mathrm{BF}$, and GM in stance phase thus suggest an unstable walking pattern.

Just as Finley et al. suggested that the elderly persons in their study were trying to preserve stability ${ }^{17)}$, the increased EMG of our patient not seen in normal adult walking may reflect an attempt to control progression and stability or the age-related changes in gait posture. "Age-related" changes in walking behavior may be caused either by the normal aging process or by disease ${ }^{12,17,19-24)}$, but it is difficult to determine which changes in gait occur as part of the normal aging process and which occur as the sequellae of pathological processes. In either case, it is necessary to evaluate all age-related changes in gait and to compare them with normal human gait, including the development of walking.

Our patient showed excessive muscular activities compared with normal adult walking at 1 month after a stroke. At 7 months after the stroke, the muscle activities indicative of unstable walking tended to decrease or disappear, although signs of excessive muscular activity still remained. When stable supported (hand cart) walking with the trunk upright was performed, the EMG patterns were closely similar to those of a stable adult walking pattern (Fig. 5). From the EMG data in this study, we saw that we could elicit a more normal adult walking pattern by substituting for missing postural and balance elements. These results suggest the validity and usefulness of evaluating the recovery of walking after a stroke by comparing EMG data with patterns seen in normal human gait, including the development of walking in early childhood.

\section{CONCLUSION}

To study the recovery of functional mechanisms of the leg muscles of an elderly man following a cerebral infarction, we studied the activities of his leg muscles during gait at 1 month, 7 months, and 1 year 7 months after his stroke.

The muscle activities at one month after the stroke closely resembled activity patterns seen in the very unstable independent gait of a one year old baby in the first month of learning to walk.

At seven months after the stroke, these abnormal patterns of activity in the tibialis anterior (TA) and lateral head of the gastrocnemius (LG) tended to decrease or disappear, although activity of the LG in the affected right leg during the latter half of swing phase still remained. Muscle activities associated with flexed knees in the vastus medialis (VM) and with a forward inclined trunk in the LG, biceps femoris (BF), and gluteus maximus (GM) were still marked in stance phase bilaterally. These EMG patterns were similar to slightly unstable 
walking seen in small children until around three years of age.

When the patient walked with the support of a hand cart and was able to hold his trunk upright, the strong burst of activity in the LG in the latter half of right swing phase disappeared, and the excessive continuous patterns of activity in the LG, $\mathrm{VM}, \mathrm{BF}$, and GM associated with forward sway of the trunk with the knees flexed in stance phase decreased or disappeared, closely resembling the stable adult walking pattern.

We recommend further study of the evaluation of recovery of walking after stroke by comparing patients' EMG patterns to those not only of normal adult human gait, but also those of the development of human walking in early childhood.

\section{Acknowledgments}

The authors wish to thank Dr. Paul D. Andrew of Hiroshima University School of Medicine for reading the manuscript and making a number of helpful suggestions and comments.

\section{REFERENCES}

1) Dettmann MA, et al: Relationships among walking performance, postural stability, and functional assessments of the hemiplegic patient. Am J Phys Med 66: 77-90, 1987.

2) Cohen L, et al: Fast walking velocity in health and Duchenne muscular dystrophy: a statistical analysis. Arch Phys Med Rehabil 65: 573-578 1984.

3) Nakamura R, et al: Relationship of muscle strength for knee extension to walking capacity in patients with spastic hemiparesis. Tohoku J Exp Med 145: 335-340, 1985.

4) Wade DT, et al: Walking after stroke: measurement and recovery over the first 3 months. Scand J Rehabil Med 19: 25-30, 1987.

5) Hamrin E, et al: Muscle strength and balance in poststroke patients. Upsala J Med Sci 87: 11-26, 1982.

6) Bohannon RW: Selected determinants of ambulatory capacity in patients with hemiplegia. Clin Rehabil 3: 47-53, 1989.

7) Suzuki K, et al: Determinants of maximum walking speed in hemiparetic stroke patients. Tohoku J Exp Med 162: 337-344, 1990.
8) Okamoto T, et al: Electromyographic study of the learning process of walking in infants. Electromyography 12: 149-158, 1972.

9) Okamoto T, et al: Human infant pre-independent and independent walking. In: Kondo S (ed), Primate Morphophysiology, Locomotor Analyses and Human Bipedalism. University of Tokyo Press, Tokyo, 1985, pp 25-45.

10) Okamoto K, et al: Electromyographic characteristics of the learning process of walking in normal infants and children. In: Yabe K, et al (eds), Adapted Physical Activity. Springer-Verlag, Tokyo, 1994, pp 137-141.

11) Okamoto T, et al: A simple procedure to attenuate artifacts in surface electrode recordings by painlessly lowering skin impedance. Electromyogr Clin Neurophysiol 27: 173-176, 1987.

12) Winter DA: The Biomechanics and Motor Control of Human Gait, 2nd ed., University of Waterloo Press, Waterloo, Ontario, 1991.

13) Basmajian JV, et al: Muscles Alive, 5th ed., Williams \& Wilkins, Baltimore, 1985.

14) Soderberg GL: Gait and gait retraining. In: Basmajian JV, Wolf SL (eds), Therapeutic Exercise. Williams \& Wilkins, Baltimore, 1990, pp 139-161.

15) Kameyama $\mathrm{O}$, et al: Electric discharge patterns of ankle muscles during the normal gait cycle. Arch Phys Med Rehabil 71: 969-974, 1990.

16) Peat M, et al: Electromyographic temporal analysis of gait: hemiplegic locomotion. Arch Phys Med Rehabil 57: 421-425, 1976.

17) Finley FR, et al: Locomotion patterns in elderly women. Arch Phys Med Rehabil 50: 140-146, 1969.

18) Knutsson E, et al: Different types of disturbed motor control in gait of hemiparetic patients. Brain 102: 405-430, 1979.

19) Craik R: Changes in locomotion in the aging adult. In: Woollacott MH, Shumway-Cook A (eds), Development of Posture and Gait. University of South Carolina Press, Columbia, 1990, pp 176-201.

20) Critchley M: Neurologic changes in the aged. J Chron Dis 3: 459-477, 1956.

21) Murray MP, et al: Walking patterns of normal men. $\mathbf{J}$ Bone Joint Surg 46-A: 335-360, 1964.

22) Murray MP, et al: Walking patterns in healthy old men. J Gerontol 24: 169-178, 1969.

23) Murray MP, et al: Walking patterns of normal women. Arch Phys Med Rehabil 51: 637-650, 1970.

24) Gabell A, et al: The effect of age on variability in gait. J Gerontol 39: 662-666, 1984. 